\title{
Cost-effectiveness of clopidogrel, prasugrel and ticagrelor for dual antiplatelet therapy after acute coronary syndrome: a decision-analytic model
}

\author{
Husam Abdel-Qadir MD, Idan Roifman MD, Harindra C. Wijeysundera MD PHD
}

\section{Abstract}

Background: The use of prasugrel or ticagrelor as part of dual antiplatelet therapy with acetylsalicylic acid after acute coronary syndrome (ACS) improves clinical outcomes relative to clopidogrel. The relative cost-effectiveness of these agents are unknown. We conducted an economic analysis evaluating 12 months of treatment with clopidogrel, prasugrel or ticagrelor after ACS.

Methods: We developed a fully probabilistic Markov cohort decision-analytic model using a lifetime horizon, from the perspective of the Ontario Ministry of Health and Long-Term Care. The model incorporated risks of death, recurrent ACS, heart failure, major bleeding and other adverse effects of treatment. Data on probabilities and utilities were obtained from the published literature where available. The primary outcome was quality-adjusted life-years (QALYs).

Results: Treatment with clopidogrel was associated with the lowest effectiveness (7.41 QALYs, 95\% confidence interval [CI] 1.05-14.79) and the lowest cost $(\$ 39601,95 \% \mathrm{Cl} \$ 8434-\$ 111186)$. Ticagrelor treatment had an effectiveness of 7.50 QALYs (95\% Cl 1.13-14.84) at a cost of $\$ 40649$ (95\% Cl $\$ 9327-\$ 111881)$. The incremental cost-effectiveness ratio (ICER) for ticagrelor relative to clopidogrel was $\$ 12205$ per QALY gained. Prasugrel had an ICER of \$57 630 per QALY gained relative to clopidogrel. Ticagrelor was the preferred option in $90 \%$ of simulations at a willingness-to-pay threshold of $\$ 50000$ per QALY gained.

Interpretation: Ticagrelor was the most cost-effective agent when used as part of dual antiplatelet therapy after ACS. This conclusion was robust to wide variations in model parameters.

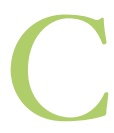
ontemporary guidelines recommend dual antiplatelet therapy with acetylsalicylic acid (ASA) and a $\mathrm{P} 2 \mathrm{Y}_{12}$ receptor antagonist for 1 year after acute coronary syndrome (ACS). ${ }^{1-3}$ The CURE (Clopidogrel in Unstable Angina to Prevent Recurrent Events) trial showed that clopidogrel reduced adverse cardiovascular events when combined with ASA for 12 months after ACS. ${ }^{1}$ However, the individual response to clopidogrel is limited by various factors. ${ }^{4}$ This has prompted research that culminated in the development of prasugrel and ticagrelor, novel $\mathrm{P} 2 \mathrm{Y}_{12}$ receptor antagonists with superior antiplatelet properties compared with clopidogrel.

The TRITON-TIMI 38 trial (Trial to Assess Improvement in Therapeutic Outcomes by Optimizing Platelet Inhibition with Prasugrel-Thrombolysis in Myocardial Infarction 38) showed that use of prasugrel after ACS significantly reduced the risk of recurrent ACS, including stent thrombosis, relative to clopidogrel. ${ }^{5}$ Similarly, the PLATO (Platelet Inhibition and Patient Outcomes) trial showed that ticagrelor reduced the risk of all-cause death after ACS relative to clopidogrel. ${ }^{6}$ Both prasugrel and ticagrelor increased bleeding rates, with a more prominent increase in risk with prasugrel. ${ }^{5,6}$
In addition to these clinical trade-offs, both agents have substantially higher acquisition costs than clopidogrel. ${ }^{7,8}$

A recent statement from the American College of Cardiology/American Heart Association emphasized the importance of evaluating the clinical benefits of health care interventions in the context of their costs. ${ }^{9}$ This enables delivery of the highest-quality health care while optimizing scarce resources. Cost-effectiveness analyses have compared clopidogrel individually with prasugrel ${ }^{10}$ and ticagrelor; ${ }^{11}$ however, none has directly compared all 3 agents against each other. Decisionanalytic modelling is well-suited to addressing this gap in knowledge, because it provides an explicit framework to inte-

\section{Competing interests: None declared.}

This article has been peer reviewed.

Correspondence to: Harindra Wijeysundera, harindra.wijeysundera@ sunnybrook.ca

CMAJ Open 2015. DOI:10.9778/cmajo.20150056 
grate all available evidence. Accordingly, we conducted an economic analysis comparing the cost-effectiveness of 12 months of treatment with clopidogrel, prasugrel or ticagrelor after an ACS, including ST-segment elevation myocardial infarction (STEMI) and non-STEMI.

\section{Methods}

\section{Study design}

We developed a fully probabilistic Markov cohort statetransition model, with a life-time horizon. Cycle length was set at 1 month. The model was analyzed from the perspective of the Ontario Ministry of Health and Long-Term Care. The 3 alternatives evaluated in the model were treatment with ticagrelor, prasugrel or clopidogrel for 12 months after revascularization with percutaneous coronary intervention in patients with an ACS. ${ }^{12-14}$ We expressed effectiveness in terms of quality-adjusted life-years (QALYs) and adjusted costs to 2012 Canadian dollars using the general Consumer Price Index from Statistics Canada.

Incremental cost-effectiveness ratios (ICERs) were calculated by ordering the 3 strategies from lowest to highest life- time cost, consistent with economic analysis conventions. We determined the ICER based on the incremental cost and effectiveness compared with the next less expensive treatment strategy. If a strategy was more effective than a more expensive alternative, it was a dominant strategy. If the ICER of a strategy was lower than its less expensive alternative, it extendedly dominated that alternative, because it represented more efficient value per unit cost. Based on guidelines, an alternative was considered to be of high value if its ICER was less than $\$ 50000$ per QALY gained $\left(1 \times\right.$ per capita gross domestic product [GDP]). ${ }^{9}$ All utilities and costs were discounted at a rate of $5 \%$ per year according to current Canadian recommendations. ${ }^{15}$

\section{Model structure}

A simplified model schematic is presented in Figure 1. Patients in the model progress through cycles of 1-month duration. All patients begin with dual antiplatelet therapy with ASA, combined with one of clopidogrel, prasugrel or ticagrelor, with the objective of completing 12 months of therapy after ACS. We assumed that every patient had successful revascularization at the time of index percutaneous coronary intervention (PCI) for their ACS.

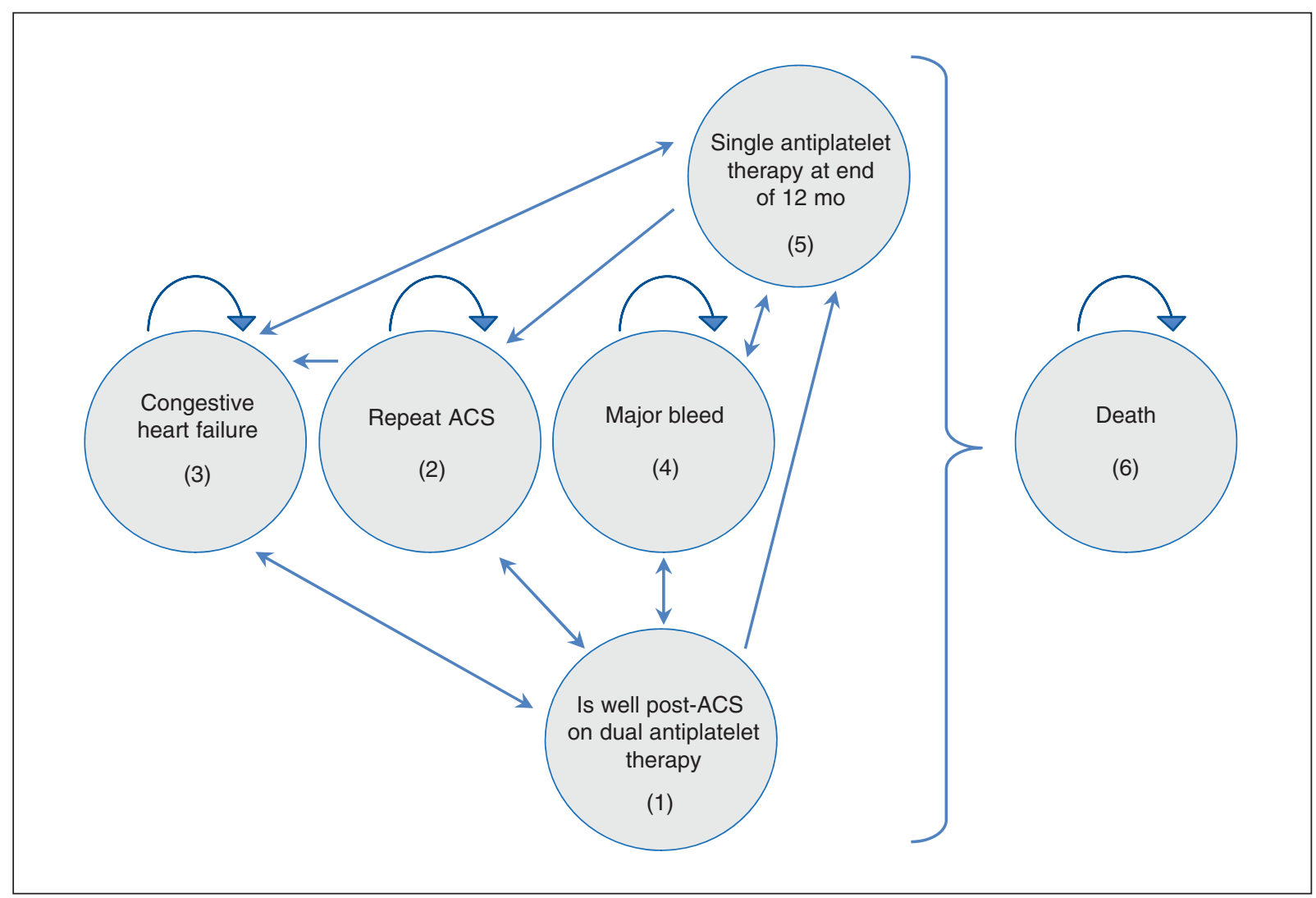

Figure 1: Simplified schematic of the decision model. This figure illustrates important events and states captured in the model. All patients enter the Markov cohort after percutaneous coronary intervention for myocardial infarction. They receive treatment with acetylsalicylic acid and one of clopidogrel, prasugrel or ticagrelor with the aim of continuing 12 months of dual antiplatelet therapy (1), after which they are transitioned to single antiplatelet therapy (5), if repeat acute coronary syndrome (ACS) does not occur (2). In addition to repeat ACS (2), patients could also have a major bleed (4). Patients could transition to a state of congestive heart failure (3), after which they could persist in that state or recover to being well post-ACS (1). Patients could die (6) at any stage of the model, with a risk dependent on age, antiplatelet therapy exposure, time since last ACS and development of congestive heart failure. Death is by definition an absorbing state. 


\section{OPEN}

Research

Within any 1 -month cycle, patients could die, develop heart failure or become free of heart failure. Events that occurred within each cycle included recurrent ACS (with possible stent thrombosis), major bleeding or minor adverse effects (minor bleeds, and ticagrelor-associated bradycardia and dyspnea). We factored discontinuation of assigned dual antiplatelet strategy into our model using rates derived from clinical trial data.

We assumed that, if patients had to stop taking clopidogrel within the first 12 months after the index ACS, the drug would be replaced with prasugrel or ticagrelor, with a $50 \%$ probability of receiving either agent. If patients were initially prescribed one of prasugrel or ticagrelor and had to stop it within the first 12 months, they were transitioned to clopidogrel. If patients had to stop $2 \mathrm{P}^{2} \mathrm{Y}_{12}$ receptor antagonists, they were classified as intolerant of dual antiplatelet therapy and maintained on single antiplatelet therapy with ASA; such patients were modelled to have higher risks of recurrent ACS and death for the first 12 months after the index ACS.

After 12 months of dual antiplatelet therapy without recurrent events, patients were transitioned to single antiplatelet therapy. If an ACS recurred, patients were transitioned to the last dual antiplatelet strategy they tolerated. Those who were intolerant of dual antiplatelet therapy received angioplasty without stenting and maintained on ASA therapy alone. These patients were modelled to have a higher risk of recurrent ACS for the subsequent 6 months.

\section{Base case}

The baseline characteristics of our base case were derived from the weighted means of the characteristics of patients enrolled in the TRITON-TIMI 38, the DISPERSE-2 (the Dose Confirmation Study Assessing Antiplatelet Effects of AZD6140 versus Clopidogrel in Non-ST-segment Elevation Myocardial Infarction) and the PLATO randomized controlled trials. ${ }^{5,6,8,16}$ The mean age was 62 years (standard deviation $12.5 \mathrm{yr}$ ); $61 \%$ were male, and $24 \%$ had diabetes.

\section{Probabilities}

Probabilities were obtained from the published literature and are listed in Table 1. . $6,17-19^{-1}$ All transition probabilities for stent thrombosis, development of heart failure, recurrent ACS and death were time-dependent based on patient age and/or time from the most recent ACS event.

The incidence of recurrent ACS, stent thrombosis and TIMI (Thrombolysis In Myocardial Infarction) major bleeding

\section{Table 1: Rates of important events and state transitions used in the model}

\begin{tabular}{|c|c|c|c|c|c|}
\hline Parameter used in model & Value, \% & $\begin{array}{l}\text { Low range } \\
\text { of sensitivity } \\
\text { analyses, \% }\end{array}$ & $\begin{array}{l}\text { High range } \\
\text { of sensitivity } \\
\text { analyses, \% }\end{array}$ & $\begin{array}{c}\text { Distribution used } \\
\text { in probabilistic } \\
\text { analysis }\end{array}$ & $\begin{array}{l}\text { Reference } \\
\text { nos. }\end{array}$ \\
\hline \multicolumn{6}{|l|}{$\begin{array}{l}\text { Transition probabilities to and from } \\
\text { heart failure }\end{array}$} \\
\hline $\begin{array}{l}\text { Monthly incidence of heart failure with no } \\
\text { recurrent ACS }\end{array}$ & 0.02 & 0 & 0.06 & Beta & 17 \\
\hline \multicolumn{6}{|l|}{ Heart failure incidence in month after ACS } \\
\hline Without stent thrombosis & 4.60 & 3.9 & 5.3 & Beta & 17 \\
\hline With stent thrombosis & 20 & 15.5 & 24.6 & Beta & 18 \\
\hline $\begin{array}{l}\text { Annual probability of transition from } \\
\text { heart failure }\end{array}$ & 57.40 & 48.8 & 66.0 & Beta & 19 \\
\hline \multicolumn{6}{|l|}{ Incidence of important clinical events } \\
\hline Incidence of recurrent ACS over $12 \mathrm{mo}$ & 7.48 & 7.1 & 7.9 & Beta & $4-6$ \\
\hline $\begin{array}{l}\text { Proportion of recurrent ACS due to stent } \\
\text { thrombosis }\end{array}$ & 20 & 0 & 49.7 & Beta & $4-6$ \\
\hline Annual incidence of major bleeding & 3.9 & 0 & 25.5 & Beta & $4-6$ \\
\hline \multicolumn{6}{|l|}{ Annual incidence of discontinuation } \\
\hline Clopidogrel & 12.4 & 12.0 & 12.8 & Beta & $4-6$ \\
\hline Prasugrel & 14.1 & 13.3 & 14.9 & Beta & 4,5 \\
\hline Ticagrelor & 13.9 & 13.4 & 14.4 & Beta & 4,6 \\
\hline \multicolumn{6}{|l|}{ Annual incidence of minor adverse effects } \\
\hline Clopidogrel & 14 & 13.4 & 14.5 & Beta & $4-6$ \\
\hline Prasugrel & 14.5 & 13.7 & 15.3 & Beta & 4,5 \\
\hline Ticagrelor & 19.8 & 19.0 & 20.6 & Beta & 4,6 \\
\hline
\end{tabular}


with clopidogrel was derived from the weighted mean of the event rates in the clopidogrel arm of the trials listed in the base case above. The incidence of these events among patients given prasugrel or ticagrelor was modelled by multiplying the baseline rate in the clopidogrel group with the corresponding hazard ratio (HR) for each event as determined from each agent's phase III trial data. Rates of minor bleeding and other minor adverse effects, as well as rates of discontinuation, were determined directly for each agent with the use the TRITON and PLATO trial data.

The baseline risk of death for patients on ASA monotherapy was derived from age- and sex-specific Ontario life tables and modified by a time-dependent change in the hazard for death based on time since the most recent myocardial infarction $^{20}$ and the presence or absence of heart failure. In each treatment arm, the risk of death was modified based on the reported HR for death reported in phase III trials of prasugrel, ticagrelor and clopidogrel (Table 2). ${ }^{4-6,20-23}$

\section{Costs and utilities}

Costs and utilities used in our study are summarized in Table $3 .^{24-30}$ Costs were reported in 2012 Canadian dollars. Unit costs for medications were obtained from the Ontario Drug Benefits Formulary. ${ }^{30}$ We assumed dispensing fees of once per 3 months ( 3 months is the maximum time frame that pharmacies prescribe medications under the Ontario Drug

\begin{tabular}{|c|c|c|c|c|c|}
\hline Parameter used in model & Value & $\begin{array}{l}\text { Low range } \\
\text { of sensitivity } \\
\text { analyses }\end{array}$ & $\begin{array}{l}\text { High range } \\
\text { of sensitivity } \\
\text { analyses }\end{array}$ & $\begin{array}{l}\text { Distribution used } \\
\text { in probabilistic } \\
\text { analysis }\end{array}$ & $\begin{array}{l}\text { Reference } \\
\text { nos. }\end{array}$ \\
\hline \multicolumn{6}{|l|}{ HR for death, by no. of years after ACS } \\
\hline$<5$ & 4.39 & 1.11 & 17.39 & Log-normal & 20 \\
\hline $5-10$ & 3.1 & 0.93 & 10.33 & Log-normal & 20 \\
\hline $10-15$ & 2.25 & 0.81 & 6.23 & Log-normal & 20 \\
\hline $15-20$ & 2.17 & 0.80 & 5.88 & Log-normal & 20 \\
\hline $20-25$ & 2.07 & 0.79 & 5.43 & Log-normal & 20 \\
\hline $25-30$ & 1 & NA & NA & NA & Assumption \\
\hline $\begin{array}{l}\mathrm{HR} \text { for death in the presence of heart } \\
\text { failure relative to its absence }\end{array}$ & 8.22 & 7.49 & 9.01 & Log-normal & 21 \\
\hline $\begin{array}{l}\text { HR for death with clopidogrel relative } \\
\text { to single antiplatelet }\end{array}$ & 0.93 for $12 \mathrm{mo}$ & 0.79 & 1.08 & Log-normal & 22 \\
\hline $\begin{array}{l}\text { HR for death with prasugrel relative } \\
\text { to clopidogrel }\end{array}$ & 0.95 & 0.78 & 1.16 & Log-normal & 4,5 \\
\hline $\begin{array}{l}\text { HR for death with ticagrelor relative } \\
\text { to clopidogrel }\end{array}$ & 0.78 & 0.69 & 0.90 & Log-normal & 4,6 \\
\hline $\begin{array}{l}\text { HR for ACS with ASA and clopidogrel } \\
\text { relative to ASA alone }\end{array}$ & $\begin{array}{l}0.77 \text { for } 12 \text { mo } \\
\text { post-ACS }\end{array}$ & 0.67 & 0.89 & Log-normal & 22 \\
\hline $\begin{array}{l}\text { HR for ACS with prasugrel relative } \\
\text { to clopidogrel }\end{array}$ & 0.75 & 0.66 & 0.85 & Log-normal & 4,5 \\
\hline $\begin{array}{l}\text { HR for ACS with ticagrelor relative } \\
\text { to clopidogrel }\end{array}$ & 0.84 & 0.74 & 0.94 & Log-normal & 4,6 \\
\hline $\begin{array}{l}\text { OR for stent thrombosis with single } \\
\text { antiplatelet relative to clopidogrel }\end{array}$ & $\begin{array}{l}13.70 \text { for } 6 \text { mo } \\
\text { post-ACS }\end{array}$ & 4.04 & 46.68 & Log-normal & 23 \\
\hline $\begin{array}{l}\text { OR for stent thrombosis with prasugrel } \\
\text { relative to clopidogrel }\end{array}$ & 0.47 & 0.35 & 0.63 & Log-normal & 4,5 \\
\hline $\begin{array}{l}\text { OR for stent thrombosis with ticagrelor } \\
\text { relative to clopidogrel }\end{array}$ & 0.74 & 0.58 & 0.95 & Log-normal & 4,6 \\
\hline $\begin{array}{l}\text { OR for major bleeding with single } \\
\text { antiplatelet relative to clopidogrel }\end{array}$ & 0.88 & 0.48 & 1.64 & Log-normal & 22 \\
\hline $\begin{array}{l}\text { OR for major bleeding with prasugrel } \\
\text { relative to clopidogrel }\end{array}$ & 1.46 & 1.15 & 1.85 & Log-normal & 4,5 \\
\hline $\begin{array}{l}\mathrm{HR} \text { for major bleeding with ticagrelor } \\
\text { relative to clopidogrel }\end{array}$ & 1.09 & 0.92 & 1.14 & Log-normal & 4,6 \\
\hline
\end{tabular}




\section{OPEN}

Research

Benefit Plan). We used monthly treatment costs of \$20.02 for clopidogrel, $\$ 80.96$ for prasugrel and $\$ 90.10$ for ticagrelor. We used the Ontario Case Costing Initiative to determine hospital care costs. ${ }^{28}$ Physician costs were obtained from the 2012 Ontario Schedule of Benefits for Physician Services. ${ }^{29}$ For each ACS, we assumed there were consultations with an emergency physician, a cardiologist and an interventional cardiologist, a diagnostic angiogram and percutaneous coronary intervention, a transthoracic echocardiogram, and 3 follow-up visits with the attending cardiologist.

We used previously described utility values for the post-MI state, with and without heart failure, as well as for ACS, and major and minor bleeding..$^{15,16,20,24,28-31}$ The utility of other non-major bleeding-related adverse effects were assumed to be equivalent to those of minor bleeding. ${ }^{22,24,26,28,30-33}$ The utility of twice-daily dosing, which is necessary for ticagrelor, was assumed to be 0.999 .

\section{Statistical analysis}

The model was fully probabilistic, with all input parameters (probabilities, utilities and costs) expressed as a distribution, with the mean or expected value and confidence intervals derived from the literature (Tables 1-3). If a confidence interval was not available, we used a conservative estimate of the variance being one-third of the mean. ${ }^{34} \mathrm{We}$ used $\beta$ distributions for probabilities and utilities, gamma distributions for costs and log-normal distributions for HRs. We ran 10000 simulations of the model, with parameter values in each simulation based on random draws from each of the distributions in the model. Our final outputs are based on the means of the results from the 10000 simulations. This probabilistic analysis allows for the full incorporation of the uncertainty of the input parameters. In addition, we expressed the degree of uncertainty by plotting a cost-effectiveness acceptability curve, which illustrates the proportion of the 10000 simulations in which clopidogrel, prasugrel or ticagrelor was the preferred option at different willingness-to-pay thresholds.

We performed one-way sensitivity analyses on all input parameters, to determine the robustness of our model. The ranges of these sensitivity analyses were based on $95 \%$ confidence intervals (CIs) determined by the distributions used for the probabilistic analysis. Given the computation intensity of

\section{Table 3: Utilities and costs used in the model}

\begin{tabular}{|c|c|c|c|c|c|}
\hline Parameter used in model & Value & $\begin{array}{l}\text { Low range of } \\
\text { sensitivity } \\
\text { analyses }\end{array}$ & $\begin{array}{l}\text { High range of } \\
\text { sensitivity } \\
\text { analyses }\end{array}$ & $\begin{array}{c}\text { Distribution used } \\
\text { in probabilistic } \\
\text { analysis }\end{array}$ & $\begin{array}{l}\text { Reference } \\
\text { nos. }\end{array}$ \\
\hline \multicolumn{6}{|l|}{ Utilities } \\
\hline $\begin{array}{l}\text { Utility of post-ACS state in absence } \\
\text { of heart failure }\end{array}$ & 0.91 & 0.56 & 1.00 & Beta & 24 \\
\hline $\begin{array}{l}\text { Utility of post-ACS state in presence } \\
\text { of heart failure }\end{array}$ & 0.55 & 0 & 1.00 & Beta & 24 \\
\hline Utility decrement associated with ACS & 0.18 for $1 \mathrm{mo}$ & 0.10 & 0.26 & Beta & 25 \\
\hline $\begin{array}{l}\text { Utility decrement associated } \\
\text { with major bleed }\end{array}$ & 0.16 for $1 \mathrm{mo}$ & 0 & 0.57 & Beta & 26 \\
\hline Utility decrements of minor adverse effects & 0.02 & 0 & 0.18 & Beta & 25,26 \\
\hline $\begin{array}{l}\text { Utility decrement associated with twice } \\
\text { daily dosing for ticagrelor }\end{array}$ & 0.0001 & 0 & 0.04 & Beta & Assumption \\
\hline \multicolumn{6}{|l|}{ Costs, \$ } \\
\hline $\begin{array}{l}\text { Monthly cost of post-ACS state in } \\
\text { presence of heart failure }\end{array}$ & 361.25 & 220 & 503 & Gamma & 27 \\
\hline $\begin{array}{l}\text { Monthly cost of post-ACS state in } \\
\text { absence of heart failure }\end{array}$ & 165.25 & 100 & 230 & Gamma & 27 \\
\hline Cost of ACS hospitalization & 9774 & 0 & 32404 & Gamma & 28 \\
\hline Hospitalization cost of major bleed & 10805 & 0 & 38255 & Gamma & 28 \\
\hline $\begin{array}{l}\text { Physician billing during ACS } \\
\text { hospitalization }\end{array}$ & 1461 & 1417 & 1505 & Gamma & 29 , assumption \\
\hline $\begin{array}{l}\text { Physician billing during hospitalization } \\
\text { for major bleed }\end{array}$ & 588 & 560 & 616 & Gamma & 29 , assumption \\
\hline Monthly cost of clopidogrel & 20.09 & 15 & 25 & NA & 30 \\
\hline Monthly cost of prasugrel & 80.96 & 70 & 92 & NA & 30 \\
\hline Monthly cost of ticagrelor & 90.10 & 79 & 101 & NA & 30 \\
\hline
\end{tabular}


the probabilistic analyses, one-way sensitivity analyses were conducted deterministically (Appendix 1, available at www. cmajopen.ca/content/3/4/E438/suppl/DC1).

The model was constructed using TreeAge Pro 2013 (TreeAge Software, Inc.). Computation was conducted using 64-core cloud computing with Amazon Web Services.

\section{Results}

\section{Base case cost-effectiveness analysis}

Clopidogrel treatment resulted in the lowest effectiveness (7.41 QALYs, 95\% CI 1.05-14.79) and the lowest cost (\$39 601, 95\% CI \$8434-\$111 186). Prasugrel treatment had an effectiveness of 7.43 QALYs (95\% CI 1.06-14.79) at a cost of \$40 422 (95\% CI \$9002-\$112 574), for an ICER of \$57 630 per QALY gained relative to clopidogrel. Ticagrelor treatment had an effectiveness of 7.50 QALYs (95\% CI 1.13-14.84) at a cost of $\$ 40649$ (95\% CI 9327-111 881), for an ICER of $\$ 3167$ per QALY gained relative to prasugrel. Prasugrel was therefore extendedly dominated by ticagrelor. When compared with clopidogrel, the ICER of ticagrelor was \$12 205 per QALY gained (Table 4). Ticagrelor was the preferred agent in $90 \%$ of the 10000 simulations at a willingness-to-pay threshold of $\$ 50000$ per QALY. When the threshold was raised to $\$ 100000$ per QALY, it was the preferred agent in $92 \%$ of the simulations (Figure 2 ).

\section{One-way sensitivity analyses}

Ticagrelor was the most cost-effective agent throughout the range of most parameters' values in the one-way sensitivity analyses. The conclusion was only sensitive to variations in the value of the HR for death associated with ticagrelor relative to clopidogrel. The ICER associated with ticagrelor relative to clopidogrel exceeded \$50 000 per QALY when the HR for death was greater than 0.89 . Ticagrelor remained the most cost-effective option when the population was restricted to only younger or older patients.

\section{Interpretation}

Our comparison of clopidogrel, prasugrel and ticagrelor suggests that ticagrelor is the most cost-effective $\mathrm{P} 2 \mathrm{Y}_{12}$ receptor antagonist for use in combination with ASA post-PCI after an ACS. This conclusion was relatively robust to variation in the values of important model parameters, with $90 \%$ of simulations supporting a preference for ticagrelor.

Clopidogrel is a second-generation thienopyridine that inhibits platelet aggregation. Along with ASA, it has been a mainstay in the management of ACS after PCI. However, a significant proportion of patients who take clopidogrel and ASA after an ACS remain at risk for subsequent adverse cardiovascular events, including death. There are several known drawbacks to clopidogrel. First, it is an inactive prodrug requiring hepatic activation via several cytochrome $\mathrm{P} 450$ enzymes. ${ }^{35}$ This activation takes time, such that maximal platelet inhibition occurs only after $4-5$ days. ${ }^{36}$ Second, the active metabolite irreversibly inhibits the adenosine diphosphate receptor, which may be associated with a greater propensity for bleeding. ${ }^{37}$ Third, there is substantial individual variability in the platelet inhibitory response to clopidogrel. Prasugrel and ticagrelor are novel $\mathrm{P} 2 \mathrm{Y}_{12}$ receptor antagonists. ${ }^{36,38}$ Like clopidogrel, prasugrel is a prodrug and an irreversible $\mathrm{P} 2 \mathrm{Y}_{12}$ inhibitor. However, there is less variability in its platelet inhibitory effect. ${ }^{36}$ Ticagrelor, a reversible and direct-acting oral antagonist of the $\mathrm{P} 2 \mathrm{Y}_{12}$ receptor, provides faster, greater and more consistent $\mathrm{P} 2 \mathrm{Y}_{12}$ inhibition than clopidogrel does. ${ }^{39,40}$ These pharmacologic properties may help explain some of the different clinical properties of these agents.

Prasugrel substantially reduces the risk of recurrent ACS and stent thrombosis. In fact, an indirect network metaanalysis showed it to be more effective than ticagrelor at reducing stent thrombosis, with an estimated odds ratio of 0.635 (95\% CI 0.433-0.932). ${ }^{4}$ However, this comes at an increased risk of bleeding. The TRITON-TIMI 38 trial indicated that the risk of any bleeding, including TIMI major bleeding, was higher with prasugrel than with clopidogrel, with HRs of 1.46 and 1.31 , respectively. ${ }^{5}$ The aforementioned network meta-analysis suggested that this higher bleeding risk persists in comparisons with ticagrelor, with an odds ratio of 1.43 (95\% CI 1.10-1.86). ${ }^{4}$ Ticagrelor, on the other hand, appears to be less potent than prasugrel with respect to reducing the risk of recurrent ACS and stent thrombosis, but it is associated with a less substantial increase in bleeding risk. Importantly, ticagrelor is associated with a significant reduction in all-cause mortality relative to clopidogrel, with an HR for death of 0.78 . This may be a consequence of a more optimal balance between these 2 competing risks. However, other pleiotropic mechanisms, such as promotion of endothelial

Table 4: Summary of cost-effectiveness analysis for the base case

\begin{tabular}{|c|c|c|c|c|c|}
\hline Strategy & Cost, $\$(95 \% \mathrm{Cl})^{*}$ & $\begin{array}{c}\text { Incremental } \\
\text { cost, \$† }\end{array}$ & $\begin{array}{l}\text { Effectiveness, } \\
\text { QALY }(95 \% \mathrm{Cl})\end{array}$ & $\begin{array}{c}\text { Incremental } \\
\text { effectiveness, QALY }\end{array}$ & $\begin{array}{l}\text { ICER, } \\
\text { \$/QALY† }\end{array}$ \\
\hline Clopidogrel & 39601 (8 343-111 186) & - & $7.41(1.05-14.79)$ & - & - \\
\hline Prasugrel & 40422 (9 002-112 574) & 821 & 7.43 (1.06-14.79) & 0.02 & $57630 \ddagger$ \\
\hline Ticagrelor & 40649 (9 327-111 881) & 227 & $7.50(1.12-14.84)$ & 0.07 & 12205 \\
\hline
\end{tabular}


adenosine activity, have been postulated to explain the survival advantage that is unique to this agent. ${ }^{41}$

Traditional cardiovascular treatment guidelines have not incorporated resource utilization and value considerations into their recommendations. However, given the finite health care resources available and the increasing costs of providing health services, there has been a recent emphasis on assessment of the cost and value of health care interventions. A recent statement from the American College of Cardiology/ American Heart Association emphasized the importance of considering cost and value when making health care decisions in the future of cardiovascular research. ${ }^{9}$ Although prasugrel and ticagrelor are clearly efficacious, it is currently unclear whether this is offset by their increased cost. The question remains whether they provide added value over clopidogrel.

Although there have been economic analyses assessing clopidogrel, prasugrel and ticagrelor, none has previously compared all 3..$^{10,11,42}$ It is important to determine the most cost-effective option among these 3 agents, which are all currently available to clinicians and policy-makers. Health care interventions with an ICER of less than $\$ 100000$ per QALY are currently defined as providing intermediate value, and those with an ICER of less than \$50 000 per QALY are thought to provide high value. ${ }^{9}$ In our analysis, ticagrelor was the most cost-effective strategy in $92 \%$ of the 10000 simulations at a willingness-to-pay threshold of $\$ 100000$ per QALY, and in $90 \%$ of the simulations at a threshold of $\$ 50000$ per QALY. This means that the model conclusions are stable to a wide range of variability in the parameters used in the model.
Our conclusions support current guidelines for nonSTEMI management, which state that it is reasonable to consider ticagrelor in preference to clopidogrel for dual antiplatelet therapy (class IIa indication) ${ }^{43}$ In contrast, current STEMI guidelines provide no preference for one agent over another. ${ }^{44}$ Our analysis provides additional cost-effectiveness data to guide decisions by hospitals and third-party payers about the adoption of ticagrelor in lieu of clopidogrel. We anticipate that this information will also be useful to authors of future treatment guidelines.

\section{Limitations}

Our study has limitations. First, our model is specific for patients with ACS who undergo PCI. We cannot extrapolate our conclusions to those receiving medical treatment.

Second, our model was a Markov cohort, and therefore it applies to the general population of patients with ACS undergoing revascularization. We did not account for individual patient variability in terms of baseline risk. Such variability may affect the overall cost-effectiveness of an agent. Investigating such subgroups should be a focus for future research.

Third, a potential limitation is that our estimates for efficacy were derived from trials in which either a 300-mg or a 600-mg loading dose of clopidogrel was used. In particular, in the TRITON-TIMI trial that evaluated prasugrel, a $300-\mathrm{mg}$ loading dose of clopidogrel was used in the control arm, whereas a 600$\mathrm{mg}$ loading dose was used in the control arm of the PLATO trial (about $19.6 \%$ of the study population) and is used in present-day practice in the setting of primary PCI for STEMI.

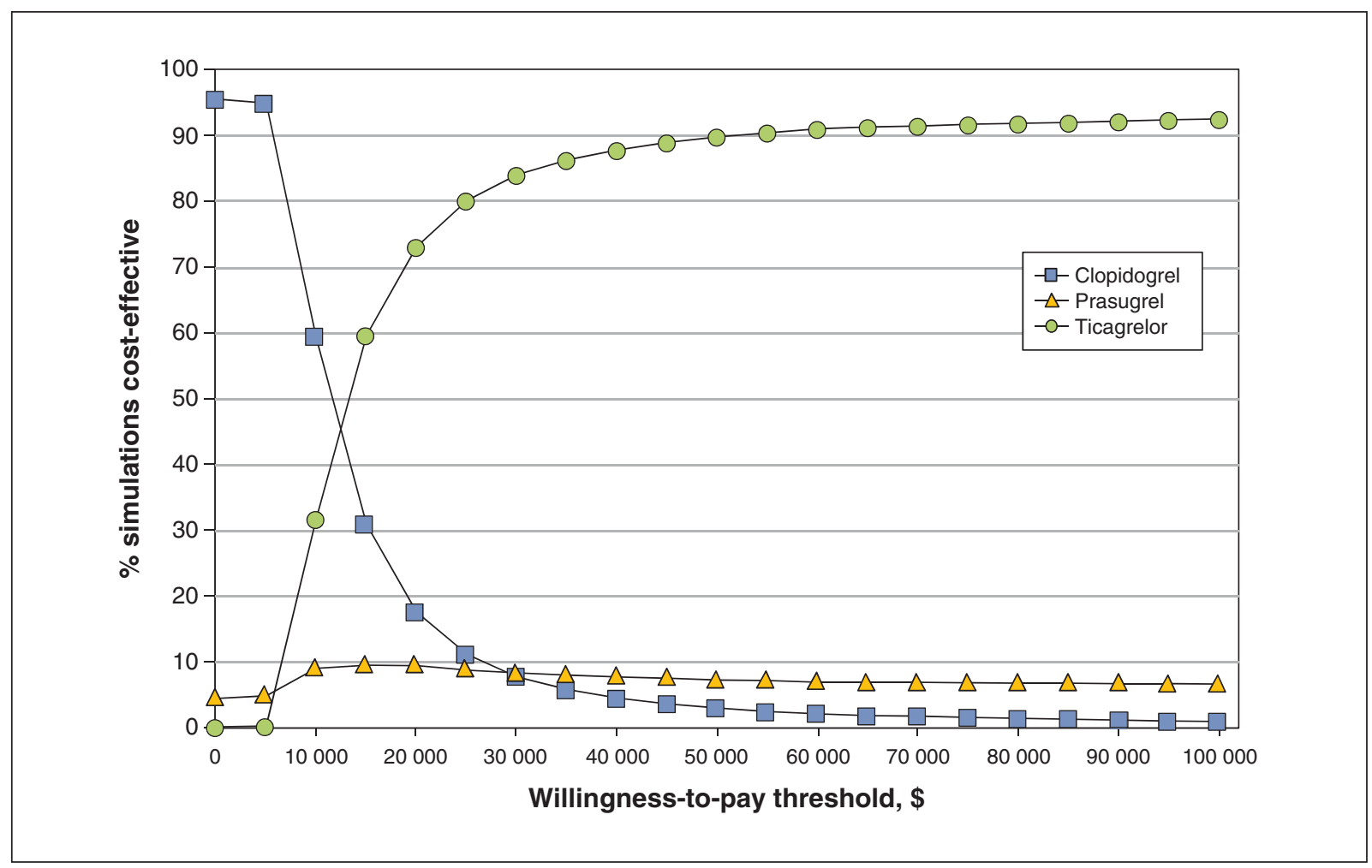

Figure 2: Cost-effectiveness acceptability curve from the probabilistic analysis, showing the proportion of 10000 simulations in which clopidogrel, prasugrel or ticagrelor was the preferred option at different willingness-to-pay thresholds (in 2012 Canadian dollars). 
The difference in death and reinfarction rates between the 2 loading doses of clopidogrel appear to be negligible..$^{45}$ Moreover, the uncertainty in the efficacy and safety estimates for both ticagrelor and prasugrel has been accounted for in the one-way and probabilistic sensitivity analyses, which showed that our conclusions were robust to wide variations in those numbers.

Fourth, we did not explicitly distinguish between different types of major bleeds in the model. However, we did account for their cumulative impact on mortality and discontinuation rates by using direct estimates of the relative risk of those events from phase III clinical trial data.

Finally, our results and conclusions are based on the current price of the 3 agents in the province of Ontario in 2015. These findings may not be generalizable to other jurisdictions. Furthermore, when the agents come off patent protection, there will likely be a substantial change in price, which would alter our results.

\section{Conclusion}

Our economic analysis indicated that ticagrelor is the most cost-effective $\mathrm{P} 2 \mathrm{Y}_{12}$ receptor antagonist when combined with ASA after ACS. These results may aid decision-makers and individual clinicians in both recommending and ultimately selecting the appropriate $\mathrm{P}_{2} \mathrm{Y}_{12}$ receptor antagonist in conjunction with ASA for dual antiplatelet therapy after ACS.

\section{References}

1. Yusuf S, Zhao F, Mehta SR, et al. Effects of clopidogrel in addition to aspirin in patients with acute coronary syndromes without ST-segment elevation. NEngl 7 Med 2001;345:494-502.

2. Pride YB, Wiviott SD, Buros JL, et al. Effect of prasugrel versus clopidogrel on outcomes among patients with acute coronary syndrome undergoing percutaneous coronary intervention without stent implantation: a TRial to assess Improvement in Therapeutic Outcomes by optimizing platelet inhibitioN with prasugrel (TRITON)-Thrombolysis in Myocardial Infarction (TIMI) 38 substudy. Am Heart 7 2009;158:e21-6.

3. Wiviott SD, Antman EM, Gibson CM, et al. Evaluation of prasugrel compared with clopidogrel in patients with acute coronary syndromes: design and rationale for the TRial to assess Improvement in Therapeutic Outcomes by optimizing platelet InhibitioN with prasugrel Thrombolysis In Myocardial Infarction 38 (TRITON-TIMI 38). Am Heart 7 2006;152:627-35.

4. Biondi-Zoccai G, Lotrionte M, Agostoni P, et al. Adjusted indirect comparison meta-analysis of prasugrel versus ticagrelor for patients with acute coronary syndromes. Int 7 Cardiol 2011;150:325-31.

5. Wiviott SD, Braunwald E, McCabe CH, et al. Prasugrel versus clopidogrel in patients with acute coronary syndromes. N Engl 7 Med 2007;357:2001-15.

6. Wallentin L, Becker RC, Budaj A, et al. Ticagrelor versus clopidogrel in patients with acute coronary syndromes. N Engl 7 Med 2009;361:1045-57.

7. O'Donoghue M, Antman EM, Braunwald E, et al. The efficacy and safety of prasugrel with and without a glycoprotein IIb/IIIa inhibitor in patients with acute coronary syndromes undergoing percutaneous intervention: a TRITONTIMI 38 (Trial to Assess Improvement in Therapeutic Outcomes by Optimizing Platelet Inhibition With Prasugrel-Thrombolysis In Myocardial Infarction 38) analysis. 7 Am Coll Cardiol 2009;54:678-85.

8. James S, Angiolillo DJ, Cornel JH, et al. Ticagrelor vs. clopidogrel in patients with acute coronary syndromes and diabetes: a substudy from the PLATelet inhibition and patient Outcomes (PLATO) trial. Eur Heart 7 2010;31:3006-16.

9. Anderson JL, Heidenreich PA, Barnett PG, et al. ACC/AHA statement on cost/ value methodology in clinical practice guidelines and performance measures: a report of the American College of Cardiology/American Heart Association Task Force on Performance Measures and Task Force on Practice Guidelines. 7 Am Coll Cardiol 2014;63:2304-22.

10. Mahoney EM, Wang K, Arnold SV, et al. Cost-effectiveness of prasugrel versus clopidogrel in patients with acute coronary syndromes and planned percutaneous coronary intervention: results from the trial to assess improvement in therapeutic outcomes by optimizing platelet inhibition with Prasugrel-Thrombolysis in Myocardial Infarction TRITON-TIMI 38. Circulation 2010;121:71-9.

11. Nikolic E, Janzon M, Hauch O, et al. Cost-effectiveness of treating acute coro- nary syndrome patients with ticagrelor for 12 months: results from the PLATO study. Eur Heart 7 2013;34:220-8.

12. Anderson JL, Adams CD, Antman EM, et al. 2011 ACCF/AHA Focused Update Incorporated Into the ACC/AHA 2007 Guidelines for the Manag ement of Patients With Unstable Angina/Non-ST-Elevation Myocardial Infarction: a report of the American College of Cardiology Foundation/ American Heart Association Task Force on Practice Guidelines. Circulation 2011;123:e426-579.

13. Bell AD, Roussin A, Cartier R, et al. The use of antiplatelet therapy in the outpatient setting: Canadian Cardiovascular Society guidelines. Can 7 Cardiol 2011;27(Suppl A):S1-59.

14. Bell AD, Roussin A, Cartier R, et al. The use of antiplatelet therapy in the outpatient setting: Canadian Cardiovascular Society Guidelines executive summary. Can 7 Cardiol 2011;27:208-21.

15. Guidelines for the economic evaluation of bealth technologies: Canada. 3rd ed Ottawa: Canada: Canadian Agency for Drugs and Technologies in Health; 2006.

16. Cannon CP, Husted S, Harrington RA, et al. Safety, tolerability, and initial efficacy of AZD6140, the first reversible oral adenosine diphosphate receptor antagonist, compared with clopidogrel, in patients with non-ST-segment elevation acute coronary syndrome: primary results of the Drosoph Inf ServPERSE-2 trial. $7 \mathrm{Am}$ Coll Cardiol 2007;50:1844-51.

17. Kelly DJ, Gershlick T, Witzenbichler B, et al. Incidence and predictors of heart failure following percutaneous coronary intervention in ST-segment elevation myocardial infarction: the HORIZONS-AMI trial. Am Heart 7 2011;162:663-70.

18. de la Torre-Hernández JM, Alfonso F, Hernandez F, et al. Drug-eluting stent thrombosis: results from the multicenter Spanish registry ESTROFA (Estudio ESpanol sobre TROmbosis de stents FArmacoactivos). 7 Am Coll Cardiol 2008;51:986-90.

19. Sleeper LA, Ramanathan K, Picard MH, et al. Functional status and quality of life after emergency revascularization for cardiogenic shock complicating acute myocardial infarction. 7 Am Coll Cardiol 2005;46:266-73.

20. Vaccaro O, Eberly LE, Neaton JD, et al. Impact of diabetes and previous myocardial infarction on long-term survival: 25 -year mortality follow-up of primary screenees of the Multiple Risk Factor Intervention Trial. Arch Intern Med 2004;164:1438-43.

21. Lewis EF, Velazquez EJ, Solomon SD, et al. Predictors of the first heart failure hospitalization in patients who are stable survivors of myocardial infarction complicated by pulmonary congestion and/or left ventricular dysfunction: a VALIANT study. Eur Heart 7 2008;29:748-56.

22. Mehta SR, Yusuf S, Peters RJ, et al. Effects of pretreatment with clopidogrel and aspirin followed by long-term therapy in patients undergoing percutaneous coronary intervention: the PCI-CURE study. Lancet 2001;358:527-33.

23. Airoldi F, Colombo A, Morici N, et al. Incidence and predictors of drugeluting stent thrombosis during and after discontinuation of thienopyridine treatment. Circulation 2007;116:745-54.

24. Tsevat J, Goldman L, Lamas GA, et al. Functional status versus utilities in survivors of myocardial infarction. Med Care 1991;29:1153-9.

25. Cost-Effectiveness Analysis Registry. Boston: Tufts Medical Center; 2013. Available: https://research.tufts-nemc.org/cear4/SearchingtheCEARegistry/ SearchtheCEARegistry.aspx (accessed 2013 Dec. 1).

26. Coleman CI, Straznitskas AD, Sobieraj DM, et al. Cost-effectiveness of clopidogrel plus aspirin for stroke prevention in patients with atrial fibrillation in whom warfarin is unsuitable. Am 7 Cardiol 2012;109:1020-5.

27. Roos JB, Doshi SN, Konorza T, et al. The cost-effectiveness of a new percutaneous ventricular assist device for high-risk PCI patients: mid-stage evaluation from the European perspective. 7 Med Econ 2013;16:381-90.

28. Ontario Case Costing Initiative. Toronto: Ontario Ministry of Health and Long-Term Care; 2013. Available: http://ophid.scholarsportal.info/details/ view.html?q=re\&uri=/phirn/occi_PHIRN_e.xml (accessed 2015 Dec. 2).

29. Schedule of benefits for physician services under the Health Insurance Act. Toronto: Ministry of Health and Long Term Care; 2012. Available: www.health.gov. on.ca/english/providers/programs/ohip/sob/physserv/physserv_nm.html (accessed 2013 Dec. 1).

30. Drugs funded by the Ontario Drug Benefit Program. Toronto: Ontario Ministry of Health and Long-Term Care; 2013.

31. Holmes KW, Maslen CL, Kindem M, et al. GenTAC registry report: gender differences among individuals with genetically triggered thoracic aortic aneurysm and dissection. Am 7 Med Genet A 2013;161A:779-86.

32. Friedel H, Delges A, Clouth J, et al. Expenditures of the German statutory health insurance system for patients suffering from acute coronary syndrome and treated with percutaneous coronary intervention. Eur 7 Health Econ 2010;11:449-55.

33. McMurray JJ, Andersson FL, Stewart S, et al. Resource utilization and costs in the Candesartan in Heart failure: Assessment of Reduction in Mortality and morbidity (CHARM) programme. Eur Heart 7 2006;27:1447-58.

34. Singh SM, Micieli A, Wijeysundera HC. Economic evaluation of percutaneous left atrial appendage occlusion, dabigatran, and warfarin for stroke prevention in patients with nonvalvular atrial fibrillation. Circulation 2013;127:2414-23.

35. Mega JL, Close SL, Wiviott SD, et al. Cytochrome p- 450 polymorphisms and response to clopidogrel. N Engl 7 Med 2009;360:354-62.

36. Cattaneo M. New P2Y(12) inhibitors. Circulation 2010;121:171-9.

37. Price MJ, Murray SS, Angiolillo DJ, et al. Influence of genetic polymorphisms 
on the effect of high- and standard-dose clopidogrel after percutaneous coronary intervention: the GIFT (Genotype Information and Functional Testing) study. 7 Am Coll Cardiol 2012;59:1928-37.

38. Cattaneo M, Podda GM. State of the art of new $\mathrm{P} 2 \mathrm{Y}_{12}$ antagonists. Intern Emerg Med 2010;5:385-91.

39. Husted S, Emanuelsson H, Heptinstall S, et al. Pharmacodynamics, pharmacokinetics, and safety of the oral reversible $\mathrm{P} 2 \mathrm{Y}_{12}$ antagonist AZD6140 with aspirin in patients with atherosclerosis: a double-blind comparison to clopidogrel with aspirin. Eur Heart 7 2006;27:1038-47.

40. Storey RF, Husted S, Harrington RA, et al. Inhibition of platelet aggregation by AZD6140, a reversible oral $\mathrm{P} 2 \mathrm{Y}_{12}$ receptor antagonist, compared with clopidogrel in patients with acute coronary syndro0mes. 7 Am Coll Cardiol 2007;50:1852-6.

41. Serebruany VL. Adenosine release: A potential explanation for the benefits of ticagrelor in the PLATelet inhibition and clinical outcomes trial? Am Heart 7 2011;161:1-4.

42. Mahoney EM, Mehta S, Yuan Y, et al. Long-term cost-effectiveness of early and sustained clopidogrel therapy for up to 1 year in patients undergoing percutaneous coronary intervention after presenting with acute coronary syndromes without ST-segment elevation. Am Heart f 2006;151:219-27.

43. Amsterdam EA, Wenger NK, Brindis RG, et al. AHA/ACC guideline for the management of patients with non-ST-elevation acute coronary syndromes: a report of the American College of Cardiology/American Heart Association Task Force on Practice Guidelines. Circulation 2014;130:e344-426.

44. O'Gara PT, Kushner FG, Ascheim DD, et al. 2013 ACCF/AHA guideline for the management of ST-elevation myocardial infarction: a report of the American College of Cardiology Foundation/American Heart Association Task Force on Practice Guidelines. 7 Am Coll Cardiol 2013;61:e78-140.

45. Mangiacapra F, Patti G, Barbato E, et al. Antiplatelet effect of 600- and 300-mg loading doses of clopidogrel in patients undergoing primary percutaneous coronary intervention for ST-segment elevation myocardial infarction: an analysis of the ARMYDA-6 MI (Antiplatelet therapy for Reduction of MYocardial Damage during Angioplasty-Myocardial Infarction) Study. Int 7 Cardiol 2012;160:213-4.
Affiliations: Institute for Clinical Evaluative Sciences (Abdel-Qadir, Roifman, Wijeysundera); Schulich Heart Program and the Sunnybrook Research Institute (Roifman, Wijeysundera); Institute for Health Policy, Management and Evaluation (Abdel-Qadir, Roifman, Wijeysundera), University of Toronto; Women's College Hospital (Abdel-Qadir), Toronto, Ont.

Contributors: Husam Abdel-Qadir and Idan Roifman are joint first authors in this paper. All of the authors contributed to the study concept and design. Husam Abdel-Qadir and Harindra Wijeysundera obtained funding for the study. Harindra Wijeysundera was the study supervisor. All of the authors contributed to the acquisition, analysis and interpretation of data, and the critical revision of the manuscript for important intellectual content. All of the authors approved the final version of the manuscript to be published and agreed to act as guarantors of the work.

Acknowledgements: Husam Abdel-Qadir is supported by a fellowship award from the Canadian Institute of Health Research. Harindra Wijeysundera is supported by a Distinguished Clinician Scientist Award from the Heart and Stroke Foundation of Canada.

Disclaimer: This study was supported by the Institute for Clinical Evaluative Sciences (ICES) which is funded by an annual grant from the Ontario Ministry of Health and Long-Term Care (MOHLTC). The opinions, results and conclusions reported in this article are those of the authors and are independent from the funding sources. No endorsement by ICES ot the Ontario MOHLTC is intended or should be inferred.

Supplemental information: For reviewer comments and the original submission of this manuscript, please see www.cmajopen.ca/content/3/4/ E438/suppl/DC1 